\title{
Author Correction: A chip-integrated coherent photonic-phononic memory
}

\author{
Moritz Merklein ${ }^{1,2}$, Birgit Stiller ${ }^{1,2}$, Khu Vu$^{3}$, Stephen J. Madden ${ }^{3} \&$ Benjamin J. Eggleton ${ }^{1,2}$
}

Correction to: Nature Communications https://doi.org/10.1038/s41467-017-00717-y, published online 18 September 2017

The original version of this Article omitted the Acknowledgements section:

"This work was sponsored by the Australian Research Council (ARC) Laureate Fellowship (FL120100029) and the Centre of Excellence program (CUDOS CE110001010). We acknowledge the support of the ANFF ACT."

This has now been corrected in both the PDF and HTML versions of the Article.

Published online: 04 January 2018

\begin{abstract}
(c) (i) Open Access This article is licensed under a Creative Commons Attribution 4.0 International License, which permits use, sharing, adaptation, distribution and reproduction in any medium or format, as long as you give appropriate credit to the original author(s) and the source, provide a link to the Creative Commons license, and indicate if changes were made. The images or other third party material in this article are included in the article's Creative Commons license, unless indicated otherwise in a credit line to the material. If material is not included in the article's Creative Commons license and your intended use is not permitted by statutory regulation or exceeds the permitted use, you will need to obtain permission directly from the copyright holder. To view a copy of this license, visit http://creativecommons.org/licenses/by/4.0/.
\end{abstract}

(C) The Author(s) 2017

\footnotetext{
${ }^{1}$ Centre for Ultrahigh Bandwidth Devices for Optical Systems (CUDOS), Institute of Photonics and Optical Science (IPOS), School of Physics, University of Sydney, Sydney, NSW 2006, Australia. ${ }^{2}$ Australian Institute for Nanoscale Science and Technology (AINST), University of Sydney, Sydney, NSW 2006, Australia. ${ }^{3}$ Centre for Ultrahigh Bandwidth Devices for Optical Systems (CUDOS), Laser Physics Centre, Research School of Physics and Engineering, Australian National University, Canberra, ACT 0200, Australia. Moritz Merklein and Birgit Stiller contributed equally to this work. Correspondence and requests for materials should be addressed to M.M. (email: moritz.merklein@sydney.edu.au) or to B.S. (email: birgit.stiller@sydney.edu.au)
} 